Article

\title{
Emergy-Based City's Sustainability and Decoupling Assessment: Indicators, Features and Findings
}

\section{Liming Zhang ${ }^{1,2}$, Bing Xue ${ }^{1, *}$, Yong Geng ${ }^{1}$, Wanxia Ren ${ }^{1}$ and Chengpeng Lu ${ }^{1}$}

1 Key Lab of Pollution Ecology and Environmental Engineering, Institute of Applied Ecology, Chinese Academy of Sciences, Shenyang 10016, China; E-Mails: annazhangliming@163.com (L.Z.); gengyong@iae.ac.cn (Y.G.); renwanxia@iae.ac.cn(W.R.); luchp.lzu@gmail.com (C.L.)

2 Institute of Applied Ecology, University of Chinese Academy of Sciences, No. 19A Yuquan Road, Beijing 100049, China

* Author to whom correspondence should be addressed; E-mail: xuebing@iae.ac.cn; Tel.: +86-24-8397-0433; Fax: +86-24-8397-0371.

Received: 2 January 2014; in revised form: 11 February 2014 / Accepted: 17 February 2014 / Published: 21 February 2014

\begin{abstract}
Decoupling human well-being and local economic growth from resources consumption and environmental degradation has been recognized as a common vision to meet global sustainability. This paper taking Shenyang city as studied case aims to measure the decoupling process by proposing a set of new emergy-based and efficiency-oriented indicators. Decoupling process was verified in period of 1995-2010, and five new indicators including economic efficiency, the environmental pressure, the emergy-based five-year yield efficiency, the investment cost for decoupling, and the job-opportunities cost for decoupling were developed and applied. The results indicate that decoupling in Shenyang shows an erratic appearance, the trajectory of economic growth, and environmental pressure show absolute decoupling, while that of economic growth and resources utilization shows frequentative bending; emergy-based economic efficiency has been improved and the environmental pressure decreased along with the economic growth but the relative job cost per unit remains almost at the same level. However, this isolated and methodology-oriented case study provided the open-mind understandings to policy-making, thus, a wider scale comparison between different cities should be carried out for more knowledge mining.
\end{abstract}

Keywords: decoupling; ecological indicator; sustainability assessment; emergy approach 


\section{Introduction}

Today, roughly half of the world's population lives in urban areas and the share is projected to reach $60 \%$ by 2030 , which will be mostly increased in developing countries [1,2]. Considering the city's role in a national governance system [3], as well as its contribution to greenhouse gas emission [4,5], resources consumption [6,7], waste generation [5,6], and pollutants emission [8], decoupling in human well-being improvement, economic growth, and ecosystem degradation with regarding to city sustainability has been taken as common recognition to meet global sustainability [9-11]. Cities attract a growing number of humans and anthropogenic assets, while natural elements suffer a decrease almost equivalent to the increase in humans and man-made assets [3,12]. During the past years, aiming to improve the understandings on a city's sustainability and served for policy-making and monitoring in reality, sets of indicators for measuring a city's sustainability have been developed by different communities $[13,14]$. For instance, Voula and Pedersen in their report recognized the need for sustainability indicators as tools for quantifying sustainability performance [15], The National Statistical Institute of Italy presented a provisional list of urban environmental sustainability indicators, which are of particular interest for cities in Italy [16]. Moreno and Martínez summarized the characteristics of urban sustainability in Mexican cities and said that sustainability indicators directly affected the development of communities, from households, colonies or neighborhoods to cities or regions [17]. Lynch et al. explored the characteristics of existing indicator systems, reviewed 22 systems with 377 indicators and a database of 145 candidate indicators were identified [18]. In general, indices for measuring sustainability consist of ecological footprint, environmental sustainability index, genuine progress indicator, human development index and city development index [14,18], and decoupling environmental pressures from economic growth has been proposed as the inter-linked objectives for enhancing cost-effective and operational environmental policies in the context of sustainability [19-22]. Previous studies on decoupling much more focused on particular sources of environmental pressure, such as natural resource utilization, energy consumption, or pollution emissions [22-24], and mostly taken countries or provinces as studied cases, while lacking of the investigations into city level decoupling research [22]. Moreover, most of the indices used in sustainability measurement separated the economic activities from natural ecosystem service, instead of combining the ecosystem service or environmental cost to economic growth [2], thus, some key questions such as "how to measure the natural values of different nonrenewable resources consumed in human activities? And how to compare the values between waste materials and environmental protection investment?" need to be addressed. Thus, a set of unified indicators need to be developed to bridge natural ecosystem service and human policy making towards to city sustainable development.

Rooted in ecology, thermodynamics, and general systems theory, Emergy is defined as the sum of all available energy inputs directly or indirectly required by a process to generate a product, which assigns value to nature's environmental effort and investment to make and support flows, materials, and services and to contribute to the economic system [6]. Emergy analysis is a technique of quantitative analysis, which determines the values of resources, services and commodities in a common unit of the solar energy it took to make them [25,26]. Thus, given the broad systemic aspects of a city's sustainability, based on emergy approach innovative indicators for measuring decoupling could be developed to achieve the target of bridging natural ecosystem service and human policy 
making towards to city's sustainability, therefore, a new set of indicators are developed in this study and applied in a case study_-Shenyang city in Liaoning Province of China for investigating the features and findings of decoupling at city level.

\section{Methodological Framework}

\subsection{Studied Area: Shenyang City}

Shenyang is the capital city of Liaoning province and is located in the central part of Liaoning province, ranges in latitude from $41^{\circ} 11^{\prime}$ to $43^{\circ} 02^{\prime} \mathrm{N}$ and in longitude from $122^{\circ} 25^{\prime}$ to $123^{\circ} 48^{\prime} \mathrm{E}$, with a total administrative area of $12,980 \mathrm{~km}^{2}$, consisting of four counties including Kangping, Faku, Xinmin, and Liaozhong, and nine districts including Shenbei, Yuhong, Heping, Shenhe, Dadong, Huanggu, Sujiatun, Hunnan, and Dongling (Figure 1). Along with its nearby cities, Shenyang is an important industrial center in China, and serves as the transportation and commercial hub of China's northeast, particularly with Japan, Russia, and Korea.

Figure 1. Location of Shenyang City in the Liaoning Province of China.

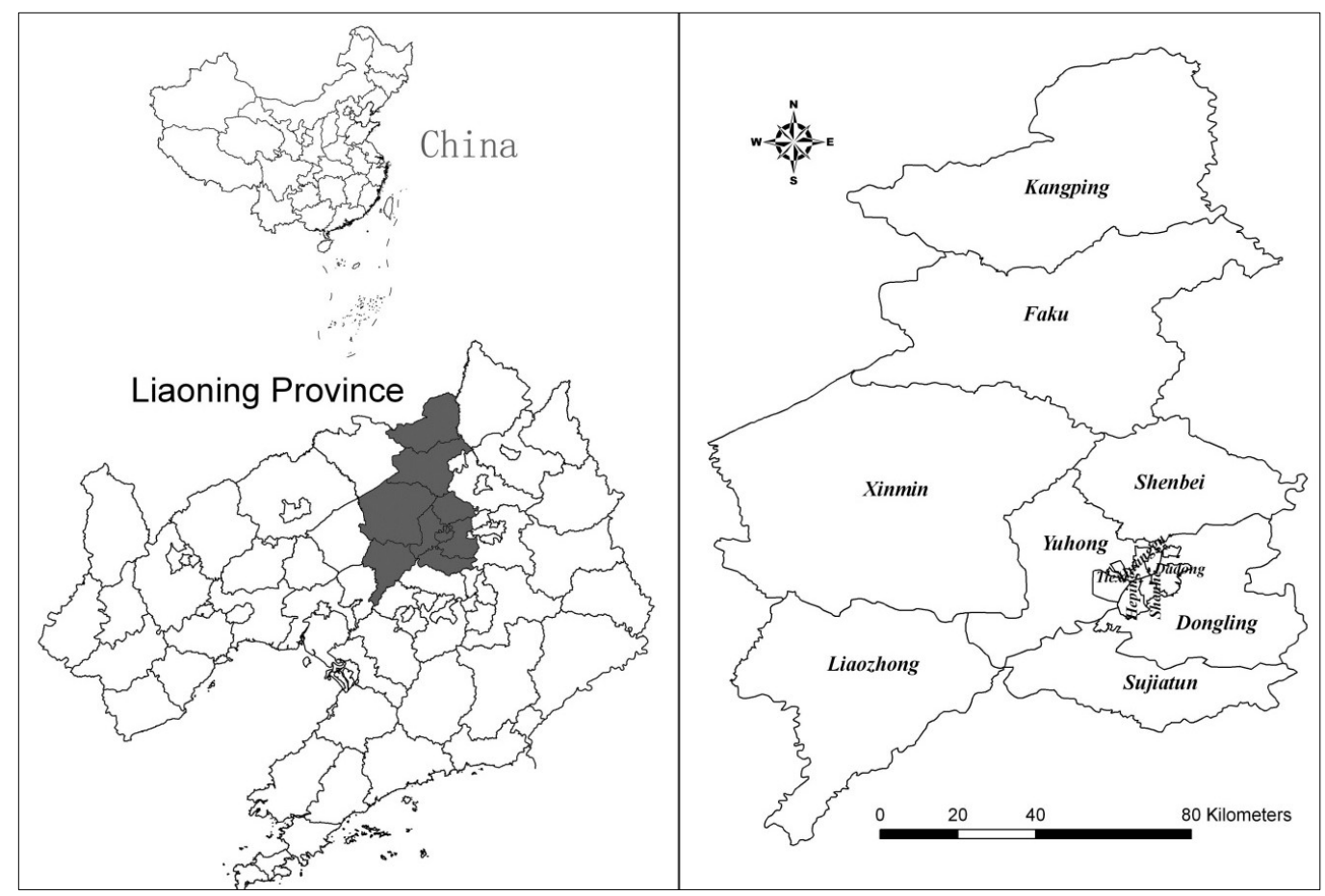

The total population was 8.10 million in 2012, and the urban population is about 5.22 million, which make Shenyang into the largest city in Northeast China and among the top ten mega-cities in China. During the period of 1995-2010, the rural population decreased from 2.52 million to 2.50 million, while the urban population increased from 4.15 million, in 1995, to 4.69 million, in 2012. In 2012, the total GDP was 660.6 billion RMB, in which the agricultural sector (primary industry, includes agriculture, forestry, livestock, fishing, and farm sideline) accounted for $4.77 \%$, the industrial sector (secondary industry, includes light industries and heavy industries) accounted for $51.30 \%$, and the service industries (tertiary industry) accounted for $43.93 \%$. The main crops grown in Shenyang are corns and rice, which in sum share about $95 \%$ of the Shenyang's total grain output. In 2003, the 
Chinese central government implemented the strategy named of "revitalizing the old industrial bases in Northeastern China" and Shenyang was selected as the prior city to demonstrate this strategy, aims to shift the industrial structure to modern forms by improving resources efficiency and reducing the environmental pressure, thus, later, Shenyang was supported to built the national comprehensive reform pilot area and demonstration zone of new industrialization in China since 2010 and Shenyang also has been identified as a member of the top 20 emerging cities in China.

\subsection{Indicators and Data Sources}

Indicators employed in this paper has categorized as two parts: the first part is about emergy indicators which are using for understanding city's ecological economic system and providing the database for following decoupling research; the second part focus on decoupling metrics, which are identified as cost- and efficient-index, based on the raw social economic data and the calculation outcomes from emergy analysis in first part. Emergy indicators including nonrenewable resources consumption, purchased input, and waste emergy are applied in this research, based on the input and output flows' analysis [27].

\subsection{Methodologies}

\subsubsection{Emergy Analysis}

The key part of emergy analysis is to transform the natural resources and capital in human activities to a unified unit, such as the solar energy (sej, solar emjoules, a popular unit using in Emergy method) $[6,25,27]$, while in which the key parameter is the emergy transformity (Trf.). Emergy analysis of Shenyang city is simplified as three aspects consisting of non-renewable resources (NRR) consumption in agricultural system, energy consumption (EoE) in industrial activities, and waste emissions (WE), and the value of the certain emergy transformity was extracted from different literatures, as shown in Table 1. Considering that the main idea of this paper is to investigate the decoupling between human well-being and local economic growth from resources consumption and environmental degradation, thus, in our study, only two main economic activities are considered which are agricultural sectors and industrial sectors. The main components representing the resources consumption with regard to agricultural sectors include nitrogenous fertilizer, phosphate fertilizer, potash fertilizer, compound fertilizer, pesticide, plastic membrane, and agricultural diesel oil, the other non-renewable materials are not considered due to the shortage of database; while, in industrial sectors, of course, there are many different non-renewable resources are consumed in the manufacturing processes, such as iron minerals, however, in this study, only the fossil fuels are considered, which were categorized as industrial energy consumption. The environmental pressures are measured by the total amount of waste emission from industrial and agricultural sectors, including solid waste, waste water and waste gas. Nevertheless, waste water from service sectors and households are not included and the municipal solid waste excludes from this study. All the raw social, economic and environmental data are extracted from the annual Statistical Yearbook of Shenyang city [28] and the public-accessible online database of the national statistical bureau of China [29]. 
Table 1. Raw indicators used for emergy analysis in Shenyang city of the year 2010.

\begin{tabular}{|c|c|c|c|c|c|c|}
\hline Note & Item & Unit & Raw data & $\begin{array}{c}\text { Transformity } \\
\text { (sej/unit) }\end{array}$ & Reference & $\begin{array}{c}\text { Emergy } \\
\text { (sej/year) }\end{array}$ \\
\hline \multicolumn{7}{|c|}{ Non-renewable resources of agriculture } \\
\hline 1 & Nitrogenous Fertilizer & $\mathrm{kg}$ & $2.86 \times 10^{8}$ & $6.62 \times 10^{12}$ & {$[30]$} & $1.89 \times 10^{21}$ \\
\hline 2 & Phosphate Fertilizer & $\mathrm{g}$ & $7.80 \times 10^{10}$ & $9.35 \times 10^{9}$ & [30] & $7.29 \times 10^{20}$ \\
\hline 3 & Potash Fertilizer & $\mathrm{g}$ & $5.73 \times 10^{10}$ & $9.32 \times 10^{8}$ & [30] & $5.34 \times 10^{19}$ \\
\hline 4 & Compound Fertilizer & $\mathrm{g}$ & $2.09 \times 10^{11}$ & $2.80 \times 10^{9}$ & [31] & $5.84 \times 10^{20}$ \\
\hline 5 & Pesticide & $\mathrm{J}$ & $9.50 \times 10^{14}$ & $1.97 \times 10^{6}$ & [31] & $1.87 \times 10^{21}$ \\
\hline 6 & Plastic Membrane & $\mathrm{g}$ & $2.29 \times 10^{10}$ & $3.20 \times 10^{9}$ & [32] & $7.32 \times 10^{19}$ \\
\hline 7 & Agricultural Diesel Oil & $\mathrm{g}$ & $8.23 \times 10^{10}$ & $2.83 \times 10^{9}$ & [33] & $2.33 \times 10^{20}$ \\
\hline \multicolumn{6}{|c|}{ Total Non-Renewable Resources (NRR) } & $5.44 \times 10^{21}$ \\
\hline \multicolumn{7}{|c|}{ Industrial Energy Consumption } \\
\hline 8 & Coal & $\mathrm{J}$ & $7.40 \times 10^{17}$ & $9.10 \times 10^{4}$ & [34] & $6.74 \times 10^{22}$ \\
\hline 9 & Cleaned Coal & $\mathrm{J}$ & $7.89 \times 10^{16}$ & $9.10 \times 10^{4}$ & [34] & $7.18 \times 10^{21}$ \\
\hline 10 & Other Cleaned Coal & $\mathrm{J}$ & $4.75 \times 10^{15}$ & $9.10 \times 10^{4}$ & [34] & $4.32 \times 10^{20}$ \\
\hline 11 & Coal Products & $\mathrm{J}$ & $9.00 \times 10^{14}$ & $9.10 \times 10^{4}$ & [34] & $8.19 \times 10^{19}$ \\
\hline 12 & Coke & $\mathrm{J}$ & $3.71 \times 10^{15}$ & $6.71 \times 10^{4}$ & [35] & $2.49 \times 10^{20}$ \\
\hline 13 & Natural Gas & $\mathrm{J}$ & $2.20 \times 10^{16}$ & $1.71 \times 10^{5}$ & [36] & $3.75 \times 10^{21}$ \\
\hline 14 & Crude Oil/petroleum & $\mathrm{J}$ & $3.04 \times 10^{16}$ & $1.48 \times 10^{5}$ & [36] & $4.5 \times 10^{21}$ \\
\hline 15 & Gasoline & g & $4.04 \times 10^{11}$ & $2.92 \times 10^{9}$ & [33] & $1.18 \times 10^{21}$ \\
\hline 16 & Kerosene & $\mathrm{J}$ & $1.50 \times 10^{15}$ & $5.50 \times 10^{5}$ & [33] & $8.27 \times 10^{20}$ \\
\hline 17 & Diesel & $\mathrm{g}$ & $4.29 \times 10^{11}$ & $2.83 \times 10^{9}$ & [33] & $1.22 \times 10^{21}$ \\
\hline 18 & Fuel Oil & $\mathrm{g}$ & $4.06 \times 10^{10}$ & $2.66 \times 10^{9}$ & [33] & $1.08 \times 10^{20}$ \\
\hline 19 & Liquefied Petroleum Gas & $\mathrm{g}$ & $2.86 \times 10^{9}$ & $3.11 \times 10^{9}$ & [33] & $8.89 \times 10^{18}$ \\
\hline 20 & Electricity & $\mathrm{J}$ & $4.10 \times 10^{16}$ & $1.74 \times 10^{5}$ & [37] & $7.14 \times 10^{21}$ \\
\hline \multicolumn{6}{|c|}{ Total Emergy of Energy (EoE) } & $9.41 \times 10^{22}$ \\
\hline \multicolumn{7}{|l|}{ Waste } \\
\hline 21 & Solid waste & $\mathrm{g}$ & $1.14 \times 10^{13}$ & $1.88 \times 10^{7}$ & [38] & $2.15 \times 10^{20}$ \\
\hline 22 & Waste water & $\mathrm{J}$ & $3.13 \times 10^{15}$ & $6.66 \times 10^{5}$ & [39] & $2.08 \times 10^{21}$ \\
\hline 23 & Waste gas & $\mathrm{m}^{3}$ & $1.30 \times 10^{11}$ & $6.68 \times 10^{10}$ & [31] & $8.69 \times 10^{21}$ \\
\hline \multicolumn{6}{|c|}{ Total Waste Emergy (WE) } & $1.10 \times 10^{22}$ \\
\hline
\end{tabular}

\subsubsection{Decoupling}

The definition of decoupling economic growth (GDP for example) from environmental problems (for example, energy consumption) was shown as in Figure 2 [40,41]. Decoupling of energy consumption growth from economic growth can be expressed as elasticity values in Equation (1):

$$
\text { GDP elasticity of energy consumption }=\% \Delta \mathrm{E} / \% \Delta \mathrm{GDP}
$$

When using economic output per capita as the $X$-axis and environmental impact as the $Y$-axis, eight logical possibilities can be distinguished. In order not to over interpret slight changes as significant, a $\pm 20 \%$ variation of the elasticity values around $1.0(0.8-1.2)$ are still regarded as coupling [40,41]: (1) Expansive negative decoupling (zone 1), GDP and environmental impact both increase, and elasticity $>1.2$; (2) Expansive coupling (zone 2), GDP and environmental impact both increase, and 
$0.8 \leq$ elasticity $\leq 1.2$; (3) Weak decoupling (zone 3), GDP and environmental impact both increase, and $0 \leq$ elasticity $<0.8$; (4) Strong decoupling (zone 4), GDP increases and environmental impact decreases, and elasticity $\leq 0$; (5) Recessive decoupling (zone 5), GDP and environmental impact both decrease, and elasticity $>1.2$; (6) Recessive coupling (zone 6), GDP and environmental impact both decrease, and $0.8 \leq$ elasticity $\leq 1.2$; (7) Weak negative decoupling (zone 7), GDP and environmental impact both decrease, and $0<$ elasticity $<0.8$; and (8) Strong negative decoupling (zone 8), GDP decreases and environmental impact increases, and elasticity $\leq 0$. Compared to this diagram, actually, our research results mostly allocated in the right part which were illustrated as zone 1 to zone 4 in Figure 2.

Figure 2. Identifications and zones of decoupling [40,41].

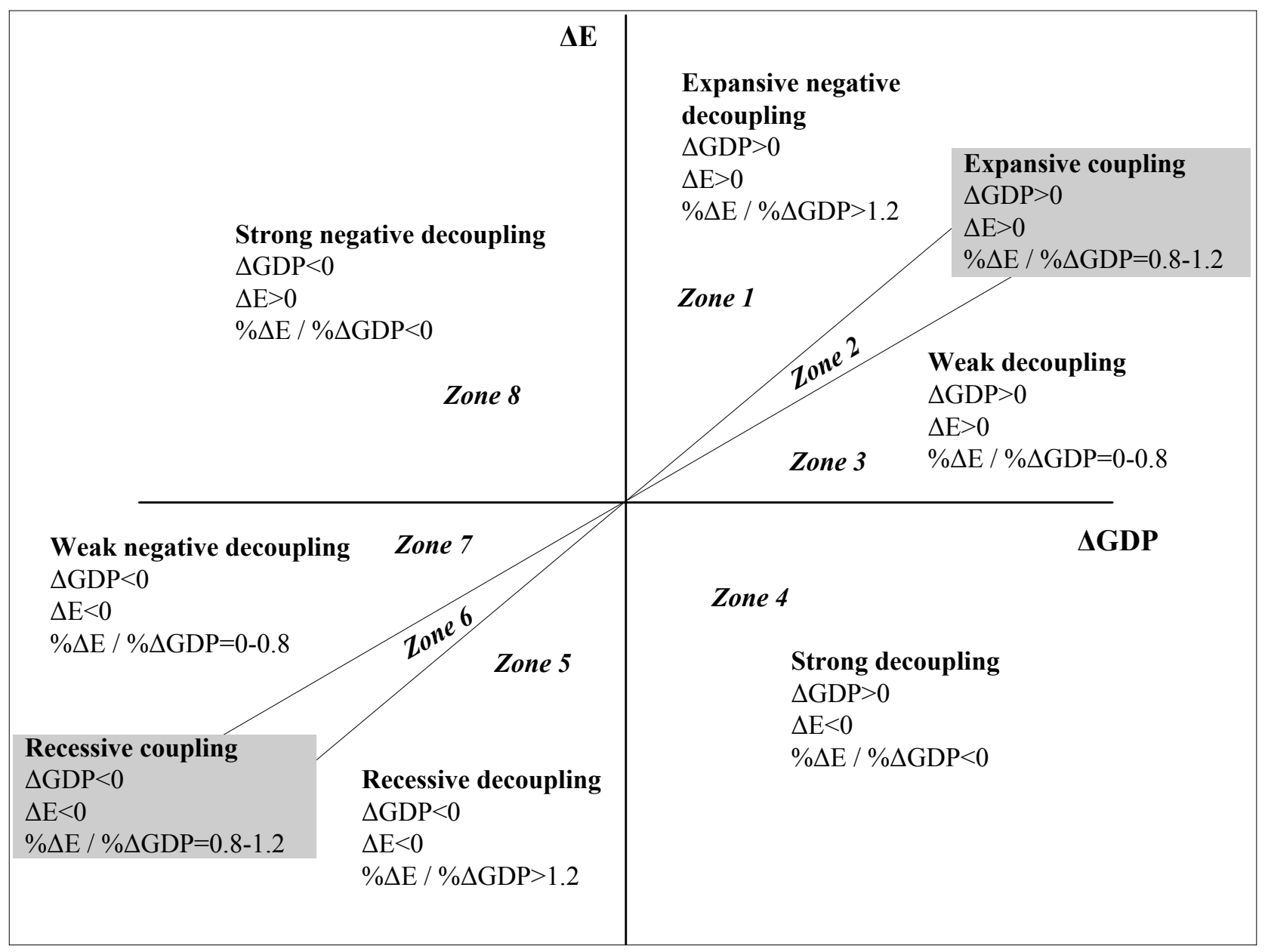

\section{Results}

The results in this section are presented as three subsections. In the first Section, 3.1, we presented the general examine results on the decoupling process in Shenyang city from 1995-2010 by using raw indicators, based on the common method which is also usually applied in other literature; the main outcome of this sector is to provide an overall understanding on the city decoupling. In the following sections, 3.2 and 3.3, we further presented the efficiency and cost analyses of decoupling process by combining the emergy approach with economic cost and job opportunities, the main outcome of these two subsections is to offer case-based answers addressing the questions frequently concerning scientific communities and local officials as well, which have been mentioned in Section 1. 


\subsection{Decoupling in Shenyang City}

Raw indicators used for illustrating the decoupling in Shenyang city consist of real GDP (RG), energy consumption (EC), and waste discharge (waste water, $\mathrm{SO}_{2}$ and solid waste), which represents economic growth, resources consumption, and environmental pressure, respectively. China's rapid economic growth has triggered fast-growing pollution and energy consumption, for example, resource utilization was almost coupled with GDP due to the high consumption and dramatic increase of mineral extraction in period of 2001-2010 [22]. As in Shenyang city, the real GDP has grown six times by the year of 2010 compared to 1995 , and energy consumption decreased $21.8 \%$ to $28.0 \%$ during 1996 to 2001 which mainly contributed by enterprises reorganization [42], volume of waste water discharged increased $120.7 \%$ and $\mathrm{SO}_{2}$ discharged has decreased to $33.6 \%$, in 2010 , compared to the data of 1995, which mainly due to technology improvement and emission reduction policies [43].

General trends of economic growth, energy consumption, and environmental pressure of Shenyang in 1995-2010 (year 1995 = 100) (Figure 3), which could be concluded that the decoupling process of Shenyang city in 1995-2010 is comprehensive complicated. The relationship between economic growth and environmental pressure shows absolute decoupling, while that of economic growth and resources utilization shows three different phases: absolute decoupling in period of 1995-2001, re-linking in period 2002-2006, and relative decoupling in period 2007-2010.

Figure 3. Trends of economic growth, energy consumption, and environmental pressure of Shenyang in 1995-2010 (year $1995=100$ ).

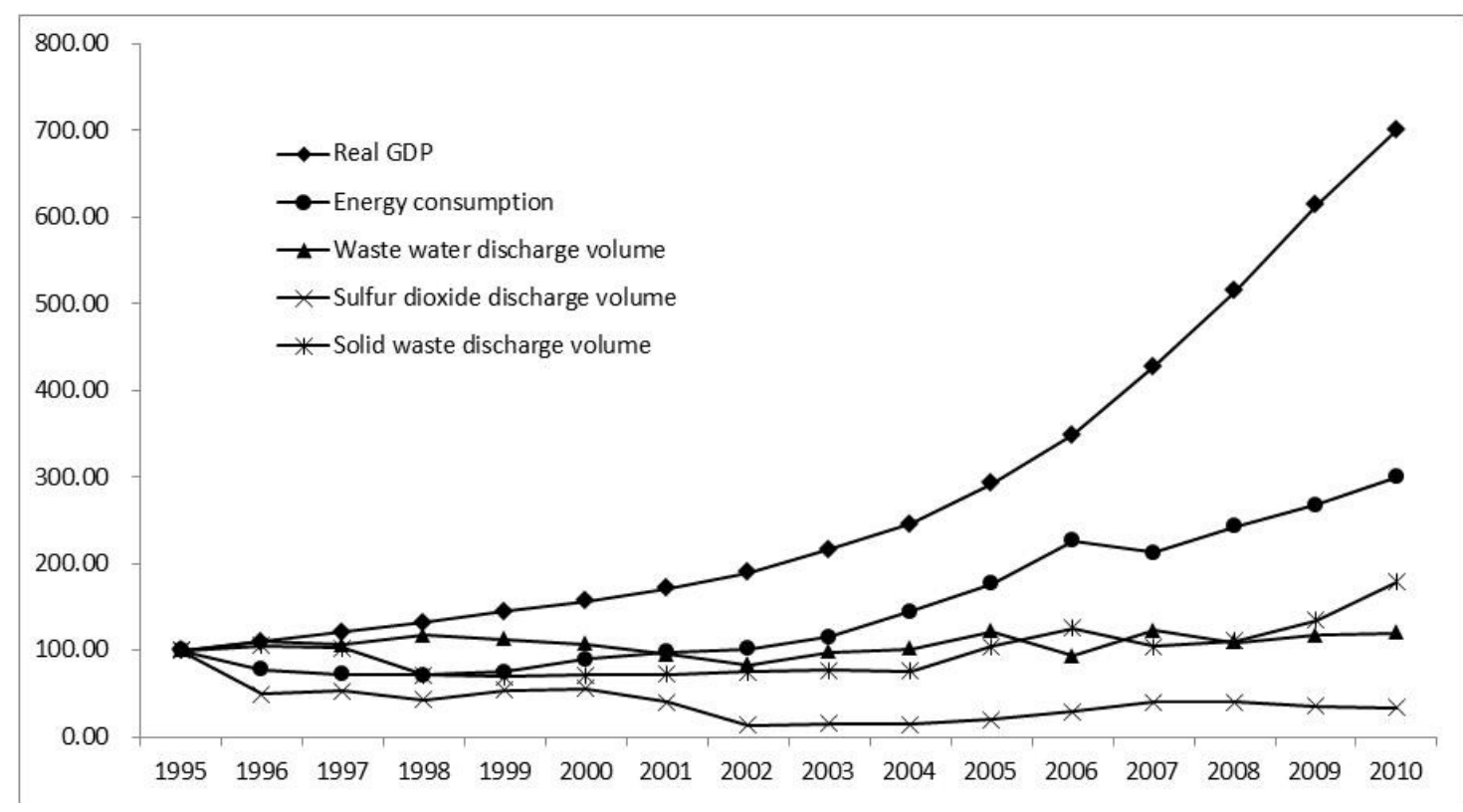

The GDP elasticity of energy consumption in Shenyang from 1995 to 2010 shows a disordered state. The trajectory started from zone 4 (1995-1996), crossed zone 3 (1998-1999) and zone 1 (1999-2000), then back to zone 2 (2001-2002), and then repeated in zone 1 to zone 3, and finally paused in zone 2 (2009-2010) (Figure 4). Different from the decoupling at national level, which usually showed as smooth curve $[2,22]$, decoupling degree of GDP elasticity of energy consumption at Shenyang has an erratic appearance. Given the background that Shenyang city, like most of the other cities in China, is 
still on the transforming phase from primary industrialization to modern industrialization (so called new-industrialization in China) [44], the situation of energy consumption sustains economic growth still exists at current and will last for a few years. With regard to the relationship between the economic growth and environmental impacts, the results show that the decoupling has happened, during 1995 to 2010, in Shenyang city, however, similar to the phenomenon shown in Figure 4, decoupling degree of economic growth and environmental impacts at city level has an erratic appearance as well. Taking the overall situation into consideration, during the period of 2000-2010, Shenyang's decoupling are mainly distributed in zone 2 (expansive coupling) and zone 3 (weak decoupling), which implies that various energy policies are strongly needed for shifting the current phase to strong decoupling (for instance, the future vision, shown in zone 4). However, given the facts that the energies are one of the main driving forces, and prerequisites as well for economic development, in order to move into zone 4, on one hand, the energy consumption structure in Shenyang city should be improved from fossil highlighted to renewable energies based, and diversity of renewable energies should be developed; on the other hand, methods on the improvement of energy efficiency and resources optimization as well should be implemented at current, given the existing potential in energy saving and materials reusing $[3,6]$.

Figure 4. The GDP elasticity of energy consumption ( $\% \Delta \mathrm{E} / \% \Delta \mathrm{GDP})$ in Shenyang.

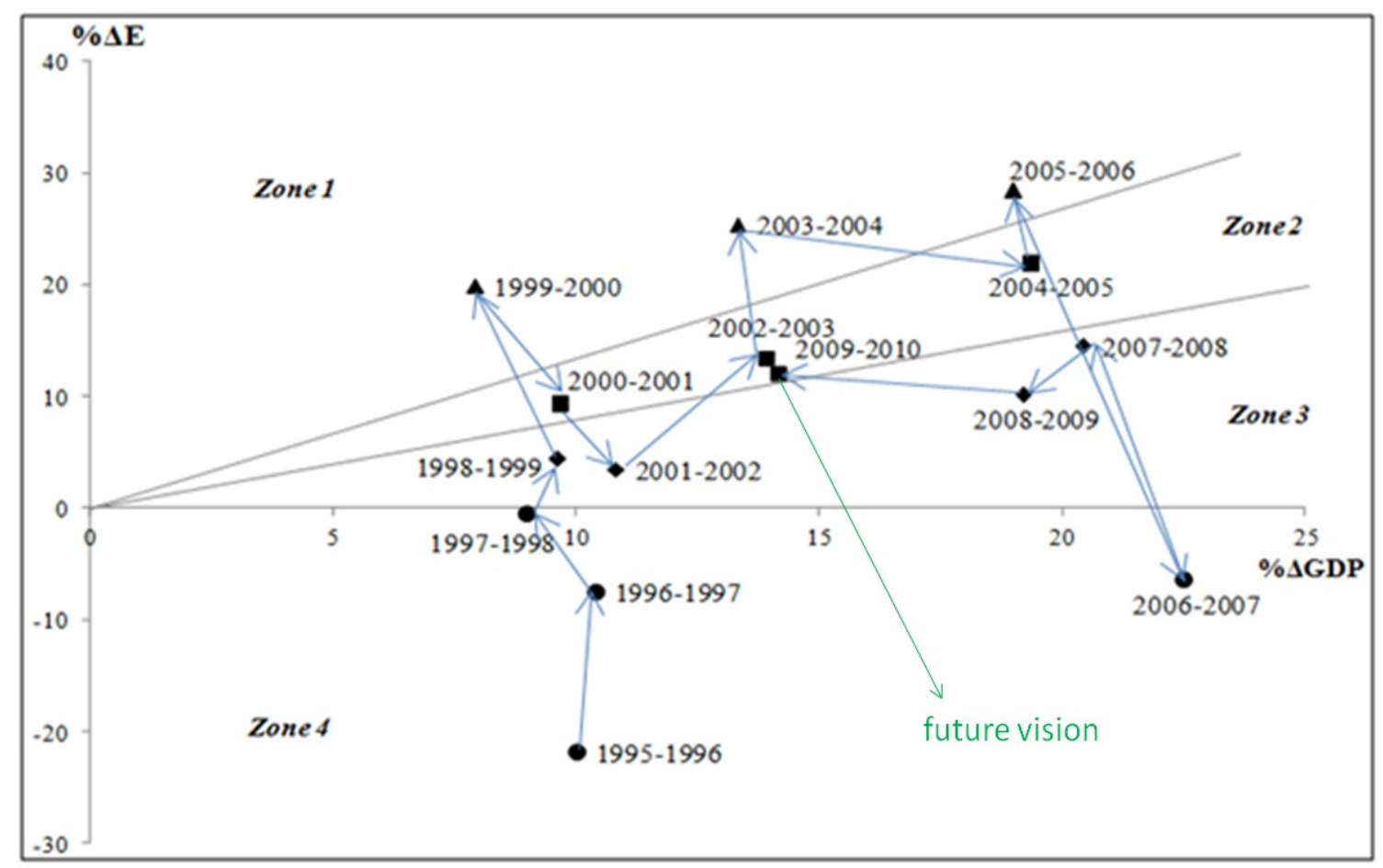

\subsection{Efficiency Analysis}

Decoupling indicators in section 3.1 indicated that, in general the decoupling process has happened in Shenyang city during the period of 1995-2010; however, such results only could provide the qualitative knowledge for understanding the dynamic trajectory of decoupling, instead of offering quantitative guidelines and answers addressing ecological system optimization and scientific-based policy making. For example, to what degree the natural ecosystem supports regional economic growth, 
and how is the eco-efficiency changing along with the decoupling process? Thus, the main resources consumed for sustaining regional economic growth were calculated based on emergy theory, and then the waste discharge, which were taken as environmental impacts of human well-beings improvement to natural ecosystem, were calculated into a single criteria emergy unit.

As shown in Table 2, the total emergy input of resources (TRC) - sum of the non-renewable resources for agricultural activities (NRR) and energy consumption for industrial activities (EoE) - increased from $2.28 \times 10^{22}$ sej in 1995 to $9.95 \times 10^{22}$ sej in 2010, among which the emergy of the non-renewable resources (NRR) increased about two times from $1.87 \times 10^{21}$ sej in 1995 to $5.44 \times 10^{21}$ sej in 2010 , while the emergy of energy consumption for industrial activities increased about 3.5 times from $2.09 \times 10^{22}$ sej in 1995 to $9.41 \times 10^{22}$ sej in 2010 . In comparison, the total waste emergy (WE) decreased from $9.67 \times 10^{22}$ sej in 1995 to $4.09 \times 10^{22}$ sej in 2000 , rebounded to $6.96 \times 10^{22}$ sej in 2010 , and then decreased to $1.10 \times 10^{22}$ sej in 2010 . Concerning on the elements aspect, the solid waste emergy contributed to a sharp drop which decreased from $8.54 \times 10^{22}$ sej in 1995 to $2.15 \times 10^{20}$ sej in 2010 , while the waste water and waste gas almost remained at the same levels compared to those in 2010 to 1995, such changes mainly resulted from the national policies of developing circular economy which aims to improve waste recycling and resources efficiency as the Circular Economy Promotion Law of China was launched in 2008 [3,6] and compulsory policies on emission reduction, which aim to reduce the main pollutants in five-year plans [8], for example, the total generation of the industrial solid waste was 7.10 million tons in 2012 , however, $94.3 \%$ of the total amount, about 6.72 million tons, has been recycled or reused due to the strategy of developing a circular economy in Shenyang.

Table 2. Emergy flow of agricultural and industrial activities in Shenyang city.

\begin{tabular}{l|c|c|c|c|c}
\hline \multicolumn{1}{c}{ Items } & Unit & $\mathbf{1 9 9 5}$ & $\mathbf{2 0 0 0}$ & $\mathbf{2 0 0 5}$ & $\mathbf{2 0 1 0}$ \\
\hline $\begin{array}{l}\text { Non-renewable resources for } \\
\text { agricultural activities (NRR) }\end{array}$ & sej & $1.87 \times 10^{21}$ & $2.20 \times 10^{21}$ & $4.45 \times 10^{21}$ & $5.44 \times 10^{21}$ \\
\hline $\begin{array}{l}\text { Energy consumption for industrial } \\
\text { activities (EoE) }\end{array}$ & sej & $2.09 \times 10^{22}$ & $2.32 \times 10^{22}$ & $3.03 \times 10^{22}$ & $9.41 \times 10^{22}$ \\
\hline Total Resources Consumption (TRC) & sej & $2.28 \times 10^{22}$ & $2.54 \times 10^{22}$ & $3.48 \times 10^{22}$ & $9.95 \times 10^{22}$ \\
\hline Solid waste (Esw) & sej & $8.54 \times 10^{22}$ & $3.60 \times 10^{22}$ & $5.11 \times 10^{22}$ & $2.15 \times 10^{20}$ \\
\hline Waste water (Eww) & sej & $2.90 \times 10^{21}$ & $1.86 \times 10^{21}$ & $2.11 \times 10^{21}$ & $2.08 \times 10^{21}$ \\
\hline Waste gas (Ewg) & sej & $8.39 \times 10^{21}$ & $3.07 \times 10^{21}$ & $1.64 \times 10^{22}$ & $8.69 \times 10^{21}$ \\
\hline Total Waste Emergy (WE) & sej & $9.67 \times 10^{22}$ & $4.09 \times 10^{22}$ & $6.96 \times 10^{22}$ & $1.10 \times 10^{22}$ \\
\hline Real GDP (RG) & Yuan & $6.73 \times 10^{10}$ & $1.05 \times 10^{11}$ & $1.97 \times 10^{11}$ & $4.71 \times 10^{11}$ \\
\hline Economic-Efficiency (EE) & Yuan/sej & $2.95 \times 10^{-12}$ & $4.15 \times 10^{-12}$ & $5.68 \times 10^{-12}$ & $4.73 \times 10^{-12}$ \\
\hline Environmental-pressure(EP) & sej/Yuan & $1.44 \times 10^{12}$ & $3.88 \times 10^{11}$ & $3.52 \times 10^{11}$ & $2.33 \times 10^{10}$ \\
\hline
\end{tabular}

Total emergy input of resources (TRC) herein means the natural resources exploitation for sustaining the economic development, and the total waste emergy (WE) means the pressure to environmental system resulted from the human economic activities, and Real GDP (RG) was used here as an indicator for measuring economic development. Thus, two new indicators including economic-efficiency (EE) and environmental-pressure (EP) were developed for quantifying a city's emergy-based decoupling degree. In formula, EE equals RG divided by TRC, which means how much economic value could be created based on one unit emergy natural resources, and EP equals WE divided 
by $\mathrm{RG}$, which indicates the environmental pressure to natural ecosystem resulting from one unit economic growth. In 2010, the emergy-based economic-efficiency (EE) of Shenyang city was $4.73 \times 10^{-12}$ Yuan/sej, improved from $2.95 \times 10^{-12}$ Yuan/sej in 1995; while the environmental pressure (EP) decreased from $1.44 \times 10^{12} \mathrm{sej} /$ Yuan in 1995 to $2.33 \times 10^{10} \mathrm{sej} /$ Yuan in 2010 , more than 60 times, which mainly resulted from the policy of developing circular economy. However, even though the amount of both waste water and gas emission almost remains the same in 1995 and 2010, shown in Table 2, in comparison, the emergy of solid waste in 1995 was 30 times to waste water and 10 times to waste gas, while in 2010 that declined to $10 \%$ and $2.45 \%$ respectively, which indicates that specific policies should be made and implemented for against the waste water discharge and air pollution at city level. The current heavy air pollution in China has demonstrated that such policies should be made as soon as possible, not only for addressing the decoupling, but also for public health.

\subsection{Cost Analysis}

In developing countries, the improvement of natural ecosystem usually should thank to the governmental investment in environmental protection, which was indicated as environmental protection investment (EPI) in the regional statistical system [6]. While in Shenyang city, the comparable environmental protection investment has decreased from $1.86 \times 10^{8}$ Yuan in 1995 to $6.41 \times 10^{7}$ Yuan in 2010. Another concern on the decoupling process is the impact on local job opportunities, which usually questioned as "does the decoupling reduce or create job opportunities?" on one hand, decoupling usually means the resources efficiency improvement, which mainly resulted from the application of advanced technologies, from this aspect, decoupling would result in job opportunities reduction; but, on the other hand, the decoupling process also encourages waste recycling for reducing the environmental pressure, which means new industries, such as environmental protection industries, would be created, and then job opportunities would be created. Thus, in order to investigate the impacts to local job opportunities, one more index, local employment, was introduced as a basic information indicator (Table 3). Here, the local employment (EPM) means the total workers number in agricultural and industrial sectors.

Table 3. Environmental protection investments and employments in Shenyang city.

\begin{tabular}{lccccc}
\hline \multicolumn{1}{c}{ Indicators } & Unit & $\mathbf{1 9 9 5}$ & $\mathbf{2 0 0 0}$ & $\mathbf{2 0 0 5}$ & $\mathbf{2 0 1 0}$ \\
\hline $\begin{array}{l}\text { Environmental protection } \\
\text { investment (EPI) }\end{array}$ & Yuan & $1.86 \times 10^{8}$ & $1.06 \times 10^{8}$ & $6.86 \times 10^{7}$ & $6.41 \times 10^{7}$ \\
\hline Employment (EPM) & capita & $2.55 \times 10^{6}$ & $2.07 \times 10^{6}$ & $1.62 \times 10^{6}$ & $1.48 \times 10^{6}$ \\
\hline
\end{tabular}

Aims to measure the social cost of meeting sustainable decoupling at city level, three more new indicators were developed, which are emergy-based five-year yield efficiency (FYE), investment cost for decoupling (IfD), and job-opportunities cost (JfD). Emergy-based five-year yield efficiency (FYE)

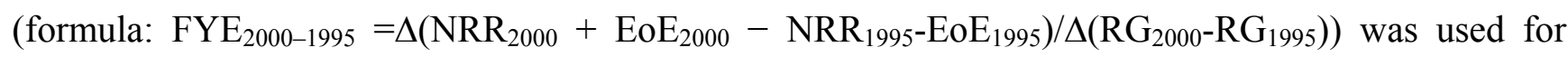
measuring the decoupling degree in 1995-2000, 2000-2005, and 2010-2005, which were $6.68 \times 10^{10} \mathrm{sej} /$ Yuan, $1.02 \times 10^{11} \mathrm{sej} /$ Yuan, and $2.36 \times 10^{11} \mathrm{sej} /$ Yuan, respectively (Table 4). The reason why we applied the "five-year yield efficiency" instead of "annual yield efficiency" is due to the long-term effect of policies implementation, and could avoid the inaccuracy resulting from the annual 
economic oscillation. However, the investment cost for decoupling (IfD $=\Delta \mathrm{EPI} / \mathrm{FYE})$, which means the investment cost for achieving one unit sej/RMB, has declined from $1.20 \times 10^{-3}$ Yuan in 1995-2000 to $1.91 \times 10^{-5}$ Yuan in 2005-2010; while the job-opportunities cost $(\mathrm{JfD}=\Delta \mathrm{EPM} / \mathrm{FYE})$, which was used for measuring the impulse to job-lost resulted from 1 unit sej/RMB decoupling, remains from $-0.72 \times 10^{-6}$ Person in 1995-2000, and $-0.59 \times 10^{-6}$ Person, in 2005-2010, which means that in comparison, $0.72 \times 10^{-6}$ Person job opportunity would be lost in achieving one unit decoupling during 1995-2000, while $0.59 \times 10^{-6}$ Person job opportunity would be lost under the same unit during 2005-2010. We could conclude that, even though the total amount of employment has decreased from $2.55 \times 10^{6}$ in 1995 to $1.48 \times 10^{6}$ in 2010 (Table 3 ), the impacts almost remained as the same, varying from $0.72 \times 10^{-6}$ during $1995-2000$ to $0.59 \times 10^{-6}$ during 2005-2010 (Table 4). All in all, we could conclude that the economic cost for addressing decoupling economic growth from environmental pressure has been decreased; even though the total employments (EPM) are reduced, the relative cost per unit (JfD) remains almost at the same level.

Table 4. Cost-oriented indicators for measuring sustainable decoupling in Shenyang city.

\begin{tabular}{llcc}
\hline \multicolumn{1}{c}{ Indicators } & \multicolumn{1}{c}{ unit } & $\mathbf{1 9 9 5 - 2 0 0 0}$ & $\mathbf{2 0 0 5 - 2 0 1 0}$ \\
\hline$\Delta(\mathrm{NRR}+$ EoE $)$ & sej & $2.54 \times 10^{21}$ & $6.47 \times 10^{22}$ \\
$\Delta \mathrm{RG}$ & Yuan & $3.81 \times 10^{11}$ & $2.74 \times 10^{11}$ \\
$\Delta$ FYE & sej/Yuan & $6.68 \times 10^{11}$ & $2.36 \times 10^{11}$ \\
$\Delta$ EPI & Yuan & $-8.04 \times 10^{7}$ & $-4.49 \times 10^{7}$ \\
$\Delta$ EPM & Yuan & $-4.80 \times 10^{5}$ & $-1.40 \times 10^{5}$ \\
IfD & Yuan & $1.20 \times 10^{-3}$ & $1.91 \times 10^{-5}$ \\
JfD & Person & $-0.72 \times 10^{-6}$ & $-0.59 \times 10^{-6}$ \\
\hline
\end{tabular}

\section{Conclusions}

Current research on a city's sustainability and decoupling of the economic growth from resource consumption and environmental degradation usually focus on either natural ecosystem aspect or human economic activities, but lack of the integrated research by bridging the human economic activities and the natural system capacity, and considering the social cost, such as government investment and impacts to regional job opportunities, which actually are of the utmost importance for policy makers and decision making. This paper introduced the emergy approach into sustainability and decoupling research, proposing a new insight into decoupling measurement with integrated quantitative modes, combing with developing new indicators, aiming towards a better understanding of the decoupling at a city level.

As shown in other developing and transition countries [21,22,44], decoupling in a transition city shows an erratic appearance. The trajectory of economic growth and environmental pressure shows absolute decoupling, while that of economic growth and resources utilization shows multi phases. Five new emergy-based indicators were developed and applied in this research for quantifying the city's sustainability and decoupling, which are the economic efficiency (EE), the environmental pressure (EP), the emergy-based five-year yield efficiency (FYE), the investment cost for decoupling (IfD), and the job-opportunities cost (JfD). In general, we could conclude that, along with the economic growth, the emergy-based economic efficiency has been improved and the environmental pressure has decreased 
during the past few decades, while the comprisable environmental protection investment decreased. Our study shows that in statistic, decoupling at a transition city level has impacts to local employment; however, even though the total job opportunities would be decreased along with the decoupling process, but the relative cost per unit remains almost at the same level. However, the outcomes of an isolated and methodology-oriented case study in Shenyang city only provide the primary understandings and implications to the policy making on decoupling; thus, a wider scale comparison between different cities should be carried out for more knowledge mining.

\section{Acknowledgments}

This research is supported by Natural Science Foundation of China $(41101126,71033004,41261112$, 71303230, and 41201584), 100 Talents Program of the Chinese Academy of Sciences (2008-318), Ministry of Science and Technology of China (2011BAJ06B01), and the Alexander von Humboldt Foundation of Germany. Special thanks go to Manuel Rivera working in Institute for Advanced Sustainability Studies Potsdam for his valuable comments.

\section{Author Contributions}

Liming Zhang contributed to data collection, data processing and draft paper; Bing Xue conducted the research and responsible for structural design, data analysis as well as paper revised; Yong Geng, Wanxia Ren and Chengpeng contributed to data analysis and paper revised.

\section{Conflicts of Interest}

The authors declare no conflict of interest.

\section{References}

1. Zhang, Y.; Zhang, J.Y.; Yang, Z.; Li, S. Regional differences in the factors that influence China's energy-related carbon emissions, and potential mitigation strategies. Energy Policy 2011, 39, $7712-7718$.

2. United Nations, Department of Economic and Social Affairs. World Urbanization Prospects, the 2011 Revision. Available online: http://esa.un.org/unup/index.html (accessed on 2 January 2014).

3. Xue, B.; Chen, X.; Geng, Y.; Guo, X.; Lu, C.P.; Zhang, Z.; Lu, C. Survey of officials' awareness on circular economy development in China: based on municipal and county level. Resour. Conservat. Recycl. 2010, 54, 1296-1302.

4. Xue, B.; Li, C.; Liu, Z.; Geng, Y.; Xi, F. Analysis on $\mathrm{CO}_{2}$ emission and urbanization at global level during 1970-2007. Adv. Clim. Change Res. 2011, 7, 423-427.

5. Xue, B.; Geng, Y.; Ren, W.; Zhang, Z.; Zhang, W.; Lu, C.; Chen, X. An overview of municipal solid waste management in Inner Mongolia Autonomous Region of China. J. Mater. Cycles Waste Manag. 2011, 13, 283-292.

6. Geng, Y.; Sarkis, J.; Ulgiati, S.; Zhang, P. Measuring China's circular economy. Science 2013, $339,1526-1527$. 
7. Kissinger, M.; Sussman, C.; Moore, J.; Rees, W.E. Accounting for the ecological footprint of materials in consumer goods at the urban scale. Sustainability 2013, 5, 1960-1973.

8. Ren, W.; Xue, B.; Zhang, L.; Ma, Z.; Geng, Y. Temporal-spatial analysis on air pollution index in China's megacities. Chin. J. Ecol. 2013, 32, 2788-2796.

9. Sorrell, S. Energy, economic growth and environmental sustainability: Five propositions. Sustainability 2010, 2, 1784-1809.

10. Santos-Martín, F.; Martín-López, B.; García-Llorente, M.; Aguado, M.; Benayas, J.; Montes, C. Unraveling the relationships between ecosystems and human wellbeing in Spain. PLoS One 2013, 8, Article e73249.

11. Liu, H.; Zhou, G.; Wennersten, R.; Frostell, B. Analysis of sustainable urban development approaches in China. Habitat Int. 2014, 41, 24-32.

12. Rees, W.E. The conundrum of urban sustainability. In How Green Is the City? Sustainability Assessment and the Management of Urban Environments; Devuyst, D., Hens, L., de Lannoy, W., Eds.; Columbia University Press: New York, NY, USA, 2001; pp. 37-42.

13. Li, Y.; Chen, W.; Chang, G. China's environmental polices evolution and circular economy development: Their implications to realize ecological modernization. China Popul. Res. Environ. 2008, $18,12-18$.

14. Hiremath, R.B.; Balachandra, P.; Kumar, B.; Bansode, S.; Murali, J. Indicator-based urban sustainability - a review. Energy Sustain. Dev. 2013, 17, 555-563.

15. Voula, M.; Pedersen, J. Urban sustainability indicators. Available online: http://eurofound.europa.eu/ pubdocs/1998/07/en/1/ef9807en.pdf (accessed on 2 January 2014).

16. National Statistical Institute of Italy. Environmental Sustainability Indicators in Urban Areas: An Italian Experience. In Proceedings of the European Statisticians, Joint ECE/Eurostat Work Session on Methodological Issues of Environment Statistics, Ottawa, ON, Canada, 1-4 October 2001.

17. Moreno, S.H.; Martínez, J. Indicators of urban sustainability in Mexico. Theor. Empir. Res. Urban Manag. 2010, 5, 46-60.

18. Lynch, A.J.; Andreason, S.; Eisenman, T.; Robinson, J.; Steif, B. Sustainable urban development indicators for the United States. Available online: http://www.penniur.upenn.edu/uploads/ media_items/sustainable-urban-development-indicators-for-the-united-states.original.pdf (accessed on 2 January 2014)

19. Organization for Economic Co-operation and Development (OECD). OECD Environmental Strategy for the First Decade of the 21st Century. Available online: http://www.oecd.org/dataoecd/ 33/40/1863539.pdf (accessed on 2 January 2014).

20. Zhang, Z. Decoupling China's carbon emissions increase from economic growth: An economic analysis and policy implications. World Dev. 2000, 28, 739-752.

21. Organization for Economic Co-operation and Development (OECD). Indicators to Measure Decoupling of Environmental Pressure from Economic Growth. Available online: http:// www.olis.oecd.org/olis/2002doc.nsf/LinkTo/sg-sd(2002)1-final (accessed on 2 January 2014).

22. Yu, Y.; Chen, D.; Zhu, B.; Hu, S. Eco-efficiency trends in China, 1978-2010: Decoupling environmental pressure from economic growth. Ecol. Indic. 2013, 24, 177-184. 
23. Bringezu, S.; Schutz, H.; Steger, S.; Baudisch, J. International comparison of resource use and its relation to economic growth - the development of total material requirement, direct material inputs and hidden flows and the structure of TMR. Ecol. Econ. 2004, 51, 97-124.

24. Sjostrom, M.; Ostblom, G. Decoupling waste generation from economic growth - a CGE analysis of the Swedish case. Ecol. Econ. 2010, 69, 1545-1552.

25. Browna, M.T.; Ulgiati, S. Understanding the global economic crisis: A biophysical perspective. Ecol. Model. 2011, 223, 4-13.

26. Brown, M.T.; Herendeen, R.A. Embodied energy analysis and emergy analysis: A comparative view. Ecol. Econ. 1996, 19, 219-235.

27. Mu, H.; Feng, X.; Chu, K. Improved emergy indices for the evaluation of industrial systems incorporating. Ecol. Eng. 2011, 37, 335-342.

28. Shenyang Municipal Government. Shenyang Statistics Yearbook 1995|2000|2006|2011; Shenyang Press: Shenyang, China, 2013.

29. National Statistical Bureau of China. Available online: http://www.stats.gov.cn/ (accessed on 2 January 2014). (In Chinese).

30. Cuadra, M.; Rydberg, T. Energy evaluation on the production, processing and export of coffee in Nicaragua. Ecol. Model. 2006, 196, 421-433.

31. Lan, S.F.; Qin, P.; Lu, H. Emergy Synthesis of Ecological Economic Systems; Chemical Industrial Press: Beijing, China, 2002; pp.335-336.

32. Brandt-Williams, S.L. Handbook of Emergy Evaluation-A Compendium of Data for Emergy Computation Issued in a Series of Folios: Folio \#4 (2nd printing): Emergy of_Florida Agriculture. Available online: http://cep.ees.ufl.edu/emergy/documents/folios/Folio_04.pdf (accessed on 2 January 2014).

33. Bastianoni, S.; Campbell, D.E.; Ridolfi, R.; Pulselli, F.M. The solar transformity of petroleum fuels. Ecol. Model. 2009, 220, 40-50.

34. Brown, M.T.; Ulgiati, S. Updated evaluation of exergy and emergy driving the geobiosphere: A review and refinement of the emergy baseline. Ecol. Model. 2010, 221, 2501-2508.

35. Odum, H.T. Environmental Accounting, Emergy and Environmental Decision Making; John Wiley \& Sons: Hoboken, NJ, USA, 1996. Available online: http://dieoff.com/emergy.pdf (accessed on 2 January 2014).

36. Brown, M.T.; Protano, G.; Ulgiati, S. Assessing geobiosphere work of generating global reserves of coal, crude oil, and natural gas. Ecol. Model. 2010, 222, 879-887.

37. Riposo, D. Integrated Energy and Environmental Analysis of Utility Scale Wind Power Production. Master Thesis, University of Maryland, College Park, MD, USA, 2008.

38. Zhou, J.B.; Jiang, M.M.; Chen, B. Emergy evaluations for constructed wetland and conventional wastewater treatments. Commun. Nonlinear Sci. Numer. Simulat. 2009, 14, 1781-1789.

39. Zhang, L.X.; Chen, B.; Yang, Z.F.; Chen, G.Q.; Jiang, M.M.; Liu, G.Y. Comparison of typical mega cities in China using emergy synthesis. Commun. Nonlinear Sci. Numer. Simulat. 2009, 14, 2827-2836.

40. Tapio, P. Towards a theory of decoupling: Degrees of decoupling in the EU and the case of road traffic in Finland between 1970 and 2001. Transp. Policy 2005, 12,137-151. 
41. Vehmas, J.; Malaska, P.; Luukkanen, J.; Kaivo-oja, J.; Hietanen, O.; Vinnari, M.; lvonen, J. Europe in the Global Battle of Sustainability: Rebound Strikes Back? Advanced Sustainability Analysis; Turun Kauppakorkeakoulu: Turku, Finland, 2003.

42. Ren, W.; Xue, B.; Geng, Y.; Sun, L.; Ma, Z.; Zhang, Y.; Mitchell, B.; Zhang, L. Inventorying heavy metal pollution in redeveloped brownfield and its policy contribution: case study from Tiexi district, China. Land Use Policy 2014, 38, 138-146.

43. Xue, B.; Mitchell, B.; Geng, Y.; Ren, W.; Müller, K.; Ma, Z.; Puppim de Oliveira, J.A.; Fujita, T.; Tobias, M. A review on China's pollutant emissions reduction assessment. Ecol. Indicat. 2014, $38,272-278$.

44. Ren, W.; Geng, Y.; Xue, B.; Fujita, T.; Ma, Z.; Jiang, P. Pursuing co-benefits in China's old industrial base: A case of Shenyang. Urban Clim. 2012, 1, 55-64.

(C) 2014 by the authors; licensee MDPI, Basel, Switzerland. This article is an open access article distributed under the terms and conditions of the Creative Commons Attribution license (http://creativecommons.org/licenses/by/3.0/). 